\title{
Short-Term Effects of Rhythmic Sensory Stimulation in Alzheimer's Disease: An Exploratory Pilot Study
}

\author{
Amy Clements-Cortes ${ }^{\mathrm{a}, \mathrm{b}, \mathrm{c}, \mathrm{d}, *}$, Heidi Ahonen ${ }^{\mathrm{b}}$, Michael Evans $^{\mathrm{c}}$, Morris Freedman $^{\mathrm{d}}$ and Lee Bartel ${ }^{\mathrm{a}}$ \\ ${ }^{\mathrm{a}}$ Music and Health Research Collaboratory, University of Toronto, Toronto, ON, Canada \\ ${ }^{\mathrm{b}}$ Wilfrid Laurier University, Waterloo, ON, Canada \\ ${ }^{\mathrm{c}}$ University of Toronto, Toronto, ON, Canada \\ ${ }^{\mathrm{d}}$ Baycrest Centre, Morris Freedman, MD, Toronto, ON, Canada
}

Handling Associate Editor: George Acquaah-Mensah

Accepted 9 February 2016

\begin{abstract}
This study assessed the effect of stimulating the somatosensory system of Alzheimer's disease (AD) patients at three stages of their illness with $40 \mathrm{~Hz}$ sound. In this AB cross-over study design, 18 participants (6 mild, 6 moderate, 6 severe) each participated in 13 sessions: one intake and 12 treatment. Treatment A consisted of $40 \mathrm{~Hz}$ sound stimulation and Treatment B consisted of visual stimulation using DVDs, each provided twice a week over 6 weeks for a total of 6 times per treatment. Outcome measures included: St. Louis University Mental Status Test (SLUMS), Observed Emotion Rating Scale, and behavioral observation by the researcher. Data were submitted to regression analysis for the series of 6 SLUMS scores in treatment A and 6 scores in B with comparison by group. The slopes for the full sample and subgroups in the $40 \mathrm{~Hz}$ treatment were all significant beyond alpha $=0.05$, while those for the DVD were not. A thematic analysis of qualitative observations supported the statistical findings. $40 \mathrm{~Hz}$ treatment appeared to have the strongest impact on persons with mild and moderate AD. Results are promising in terms of a potential new treatment for persons with AD, and further research is needed.
\end{abstract}

Keywords: Alzheimer's disease, auditory stimulation, cognition, vibration

\section{INTRODUCTION}

Dementia is the most common form of mental health disorder, affecting approximately $15 \%$ of Canadians over the age of 65 [1]. Alzheimer's disease $(\mathrm{AD})$ is the most prevalent type of dementia [2] and presents a substantial challenge for the aging population, and subsequently, it has significant implications for the health care system.

A number of studies have examined pharmacological treatments in $\mathrm{AD}$, and future research will continue to explore this avenue. However, there

\footnotetext{
*Correspondence to: Amy Clements-Cortes, PhD, 56 Destino Crescent, Woodbridge, ON, L4H 3E1, Canada. Tel.: +1 905417 4486; E-mail: a.clements.cortes@utoronto.ca.
}

is a growing trend to explore non-pharmacological therapies and their efficacy is growing in terms of helping caregivers of persons with $\mathrm{AD}$ to manage the disease's symptoms. These alternative health care options include: cognitive training, music therapy, aromatherapy, pet therapy, reflexology, acupuncture, chiropractic, and naturopathy [3-5]. Research into non-pharmacological treatments offers patients and caregivers additional choices in managing symptoms and potentially slowing the progression of the disease [6]. This is particularly important since the effectiveness of current pharmacological treatments is limited.

With the incidence of $\mathrm{AD}$ and other forms of dementia expected to increase by $100 \%$ around the globe by 2050 [7], further research into new 
treatments is needed to enhance quality of life for affected persons and keep them engaged well into the progression of the disease. Cognitive clarity and short-term memory are particularly important factors in quality of life and heavily involved in the preservation of relationships and independence.

There is substantial evidence that coherent $40 \mathrm{~Hz}$ neural oscillation is a fundamental frequency of healthy brain activity and of intra-brain communication [8-10]. Further it has been determined that the $40 \mathrm{~Hz}$ oscillation is a covariate of cognition and not simply an induced sensory phenomenon [9]. This is important for persons diagnosed with $\mathrm{AD}$ since they appear to have lower levels of $40 \mathrm{~Hz}$ oscillation than persons of the same age with 'normal' brains [8]. Important for the premise of the present study is the finding that auditory stimulation in 'normal' persons can reset the $40 \mathrm{~Hz}$ oscillation [9]. More recently, it has been shown that $40 \mathrm{~Hz}$ steady state oscillation can be stimulated or "driven" with vibration [11]. The premise of this study, therefore, is that sound driven vibrotactile stimulation of the somatosensory system at $40 \mathrm{~Hz}$ can increase the electropotential power of the steady state $40 \mathrm{~Hz}$ oscillation in AD patients and, consequently, there may be improvements in cognition. No such research has previously been conducted, hence the importance of this exploratory pilot study.

Rhythmic sensory stimulation (RSS), the treatment technique used in the present study, is a conceptual extension of Low Frequency Sound Stimulation (LFSS). Vibroacoustic Therapy (VAT) has been considered and studied primarily as a vibrotactile stimulation at the physical-muscle level. RSS includes all the potential of LFF and VAT plus it emphasizes the potential stimulation of neural activity with sound applied rhythmically to the body or auditory system.

The terms VAT and physioacoustic therapy (PAT), as well as LFSS [12-14], are often used interchangeably and refer to the process of deeply stimulating the mechanoreceptors in the body and cellular structures providing a means of blocking the transmission of pain while also increasing circulation. Chairs or beds that are fitted with low frequency transducers are the usual devices through which LFSS is delivered. This type of therapy has been shown to improve mobility [15], increase circulation [16], and help decrease pain [17], low-density lipoprotein levels, and blood pressure $[14,16]$, as well as to reduce muscle strain and stiffness [16]. LFSS stimulates mechanoreceptors and, like RSS, is acknowledged to drive a neural response that can contribute to increased neural rhyth- mic oscillatory coherence [11]. RSS has been shown to drive brain activity at selected frequency levels in the gamma range, e.g., $40 \mathrm{~Hz}$ [8]. Currently there is substantial interest and research energy focused on the use of RSS as a treatment for conditions linked to brain dysrhythmias, including: neuropathic pain, AD, Parkinson's disease, depression, and even tinnitus [17].

\section{METHOD}

\section{Objective}

The specific aim was to conduct a pilot study evaluating the effects of RSS at $40 \mathrm{~Hz}$ in AD with the intent of informing the parameters of a larger proof of concept study followed by a clinical trial. The purpose of this study was to test $40 \mathrm{~Hz}$ RSS as a means of improving alertness, cognition, and short-term memory in AD.

\section{Hypothesis}

The hypothesis is that repeated sessions of somatosensory RSS at $40 \mathrm{~Hz}$ will drive an increase in neural rhythmic oscillatory coherence at the $40 \mathrm{~Hz}$ gamma level and will consequently contribute to improved cognition in patients at stages 1,2 , and 3 of $\mathrm{AD}$ when compared with repeated sessions of non-rhythmic visual stimulation.

\section{Participants}

Eighteen participants (10 male, 8 female, ages 59-93) diagnosed with AD were recruited and completed all treatment sessions for this study ( 6 mild, 6 moderate, and 6 severe). All participants were recruited from the healthcare facility, which provides a continuum of care for both in- and outpatients. An additional two participants who began the study withdrew, one mild female AD (withdrew after 4 DVD sessions) and one moderate female AD (withdrew after 2 DVD sessions). Data from these two participants were not included in the analysis. See Table 1 for the participant summary.

Inclusion criteria included: (1) diagnosis of $\mathrm{AD}$ based upon NIA-AA core clinical criteria for probable AD dementia [18]; (2) diagnosis made by consensus involving at least two memory clinic physicians (neurologists, geriatric psychiatrists, or geriatrician) and a neuropsychologist; (3) CT or MRI that was normal or showed atrophy. Nonspecific 
white matter changes suggestive of cerebrovascular disease and lacunar infarcts without history of clinical stroke are common with aging, and did not exclude subjects because allowing these neuroimaging findings made participants more representative of the general population. Exclusion criteria included mood, anxiety, psychotic or substance abuse disorders [19], severe systemic disease (e.g., renal failure), or neurological disorder other than AD.

Since a pragmatic purpose of this study for the long-term music medicine research program was to demonstrate a response effect of RSS to inform the next proof of concept study, representation from different stages of $\mathrm{AD}$ was crucial. Six subjects per group was considered adequate to indicate potential effect resulting in a total sample of 18 .

\section{Ethical considerations}

The study was approved by the Baycrest Research Ethics Board and the University of Toronto Ethics Board. Informed consent was obtained from all substitute decision makers prior to treatments and testing. Participants were read the ascent letter and given a copy.

A number of risks and possible discomforts were discussed with participants and substitute decision makers. These included: feeling motion sickness, dizziness, feelings of light-headedness, or nausea during the low frequency sound wave vibrations. Participants were also informed that the risk of side effects may be heightened in users of painkillers, users of ergogenic aids (performance-enhancing mechanical, pharmacological, physiological, nutritional aids), sleep medication, psychiatric medications, sufferers of acute inflammation, patients with flu-like symptoms, patients who have had hemorrhages, and those with severe cardiac complaints.

\section{Procedure}

Participants took part in a total of 13 sessions each. During the intake session, participants completed: (1) the Saint Louis University Mental Status (SLUMS) test to obtain a baseline score; and (2) background information on the person. Each participant then received 12 treatment sessions: 6 sessions of visual stimulation and 6 sessions $40 \mathrm{~Hz}$ treatment. Participants were randomized into one of two groups within a cross-over design. Group one received 6 sessions of visual stimulation followed by 6 sessions of $40 \mathrm{~Hz}$ treatment; and group two received 6 sessions of $40 \mathrm{~Hz}$ treatment followed by 6 sessions of visual stimulation. There was a wash-out period of a minimum of 2 days between the cross-over. Please note that none of the participants left sessions before either treatment was completed, and the SLUMS test was administered.

\section{Interventions}

RSS stimulation: $40 \mathrm{~Hz}$ RSS was applied for $30 \mathrm{~min}$ through vibrotactile somatosensory stimulation administered with the NextWave chair [20], the most medically established device for vibroacoustic somatosensory stimulation at the time of this study. It produces computer generated and controlled low-frequency sinusoidal sound waves broadcast through the chair's six low-frequency speakers providing full-body vibrotactile stimulation with potential of frequencies between $27-113 \mathrm{~Hz}$. The device is approved by the Canadian Standards Association (CSA) (Canada), Food and Drug Administration (FDA) (USA), and British Standards Institution (BSI) (UK) and is classified as II (low risk, noninvasive). The 30-min treatment used a purely sinusoidal $40 \mathrm{~Hz}$ stimulation programmed to be produced by all the speakers in the chair.

The stimulation software used in this study was PhysAc.Net (2005), running on a laptop with Windows 95 . The RSS treatment was designed by the co-investigators specifically for this study. The program parameters include (1) cycle of amplitude modulation, (2) direction of sound movement, (3) sound pressure, and (4) frequency.

(1) Cycle of amplitude modulation (CAM): The CAM systematically varied the amplitude of the low frequency sound impulse from silence (amplitude $=0 \mathrm{~dB})$ to the set maximum $(n>0 \mathrm{~dB})$ and back to silence. The length of this CAM was set at $2.3 \mathrm{~s}$.

(2) Direction of sound wave movement. The direction of the sound changed every $2 \mathrm{~min}$. During the first 2 min, constant sound came from all speakers, during the next 2 min the sound progressively moved from head to legs, and during the last 2 min sound moved from legs to head. This cycle repeated over and over during the program.

(3) Sound pressure. Sound pressure with the PhysAc and Nextwave is set for each of the speaker locations: legs, thighs, back, and shoulder/neck. Maximum sound pressure levels (amplitude peaks), for the neck area, ranged between 102.4 to $103.2 \mathrm{dBc}$ (Decibels relative to carrier); for the back area, between 104.7 to $105.4 \mathrm{dBc}$; for the thighs area, between 109.1 
to $109.6 \mathrm{dBc}$, and for the legs area, between 104.9 to $105.3 \mathrm{dBc}$. These values were standardized for the study. Each participant received the same program. Vibration metrics of displacement, velocity, and acceleration were not measured.

(4) Frequency. The operational treatment frequency in this study was $40 \mathrm{~Hz}$, but to avoid any mechano-receptor numbing effect, and because the PhysAc software programming does not use exact $40.00 \mathrm{~Hz}$, the frequency was set to change between $39.96 \mathrm{~Hz}$ and $40.06 \mathrm{~Hz}$. These frequencies were modulated with the amplitude cycle for a 2.3-s repeating cycle. These settings were consistently utilized in the study with all the participants.

Visual stimulation: Participants sat on the NextWave chair, while the chair was not turned on, and watched visual stimuli on a television screen with images of ocean waves and/or nature. Several DVDs from the Power Flow Network [21] provided the source of this stimulation. These DVDs were created for the AD population.

Sessions were provided two times per week for 6 weeks. Each session lasted for 35-40 minutes and included either $30 \mathrm{~min}$ of visual stimulation or $30 \mathrm{~min}$ of $40 \mathrm{HZ}$ stimulation.

\section{Outcome measures}

Three measures were used to assess changes in alertness, cognition, and short-term memory. The first two tests were selected due to their wide use in $\mathrm{AD}$ in both clinical screening and research.

1. Saint Louis University Mental Status (SLUMS) [22]: The SLUMS is intended to screen individuals for the presence of cognitive deficits, and to identify changes in cognition over time. The SLUMS consists of 11 items, and measures aspects of cognition including orientation, short-term memory, calculations, naming of animals, clock drawing and recognition of geometric figures. Scores range from 0 to 30, with scores of 27-30 considered normal in a person with a high school education. Scores between 21 and 26 suggest mild neurocognitive disorder and scores between 0 and 20 indicate dementia.

2. Observed Emotion Rating Scale [23]. This tool assesses anger, pleasure, anxiety/fear, sadness, and alertness.

3. Researcher Observation: Observation was included to record any significant changes in body language, mood, memory, alertness, and cognition during the stimulation sessions. (See Supplementary Material: RSS and AD Session Observation).
The tests were administered as follows: (1) SLUMS 13 times - Pre-study and after each stimulation session; (2) Observed Emotion Rating Scale (pre and post stimulation sessions); (3) Research Observation (recorded during each stimulation session).

\section{Data analysis}

Quantitative data: To evaluate the effect of the two treatments on cognition, a regression analysis was performed for the series of SLUMS scores (prestudy assessment score plus a score for each of the 6 sessions in each of the two treatments $(40 \mathrm{~Hz}$ or DVD) for a total of 13 individual scores). An analysis of variance (ANOVA) was conducted with variables including treatment (40 Hz or DVD) and group (mild, moderate, severe AD). The regression analysis fitted straight lines to each series of treatment scores and comparison focused on slope of the regression line. Following this, analysis was undertaken to assess if there were any interactions among group and treatment, as well as the form of any main effects.

Qualitative data: Research observation notes were analyzed by the therapist who provided sessions and two research assistants (RAs) blind to the treatment interventions. The RAs were accredited Music Therapists (MTA), familiar with this client population, and had experience coding qualitative data; and thus were able to consider the results objectively. Individually the therapist and the two RAs considered the observation transcripts and identified significant behaviors, reports, or statements. From these behaviors/statements/reports, descriptive codes were created that summarized the primary meaning underlying the statements. After all observation transcripts were analyzed in this manner, the codes where organized into a smaller number of comprehensive themes to identify behaviors and responses during the treatment sessions. The therapist and RAs each independently reviewed the final list of themes in relation to the observation transcripts to confirm accurate interpretation. Following this, the three met as a team to present and discuss their results. The therapist who provided sessions made the final decisions regarding the themes that were chosen.

\section{RESULTS}

\section{Quantitative results}

Table 2 provides a summary of the participant demographics and test scores. The R-squared was 
Table 1

Participant summary

\begin{tabular}{|c|c|c|c|c|c|c|c|c|c|}
\hline Diagnosis & $\begin{array}{c}\text { Total Number of } \\
\text { Participants }\end{array}$ & Age Range & Male & $\begin{array}{l}\text { Male Age } \\
\text { Range }\end{array}$ & Female & $\begin{array}{c}\text { Female Age } \\
\text { Range }\end{array}$ & $\begin{array}{c}\text { SLUMS Score } \\
\text { Range }\end{array}$ & $\begin{array}{c}\text { SLUMS Score } \\
\text { Range Male }\end{array}$ & $\begin{array}{l}\text { SLUMS Score } \\
\text { Range Female }\end{array}$ \\
\hline Mild & 6 & -93 & 4 & $59-90$ & 2 & $80-93$ & $4-21$ & 21 & 16 \\
\hline Moderate AD & 6 & $72-90$ & 3 & $78-82$ & 3 & $72-90$ & $6-19$ & $7-19$ & $6-13$ \\
\hline Severe AD & 6 & $76-89$ & 3 & $76-86$ & 3 & $85-89$ & $2-12$ & $2-12$ & $3-11$ \\
\hline
\end{tabular}

Table 2

Participant demographics

\begin{tabular}{|c|c|c|c|c|c|c|c|c|}
\hline Participant & Gender & Age & $\begin{array}{c}\text { MMSE } \\
\text { Available at } \\
\text { intake as indicated } \\
\text { on the client chart* }\end{array}$ & $\begin{array}{l}\text { Diagnosis } \\
\text { At intake as indicated } \\
\text { on client chart: Mild, } \\
\text { Moderate, } \\
\text { or Severe AD }\end{array}$ & $\begin{array}{l}\text { SLUMS Score } \\
\text { Intake }\end{array}$ & $\begin{array}{c}\text { SLUMS Score } \\
\text { Range }\end{array}$ & $\begin{array}{l}\text { SLUMS Score } \\
\text { Range DVD }\end{array}$ & $\begin{array}{l}\text { SLUMS Score } \\
\text { Range } 40 \mathrm{HZ}\end{array}$ \\
\hline 1 & Male & 68 & 16 & Mild & 6 & $4-10$ & $5-10$ & $4-10$ \\
\hline 2 & Male & 75 & 20 & Mild & 5 & $5-11$ & $5-6$ & $6-11$ \\
\hline 3 & Female & 72 & 18 & Moderate & 6 & $6-9$ & $6-7$ & $6-9$ \\
\hline 4 & Female & 90 & 16 & Moderate & 8 & $8-11$ & $8-9$ & $9-11$ \\
\hline 5 & Male & 90 & 16 & Mild & 12 & $12-21$ & $12-17$ & $12-21$ \\
\hline 6 & Male & 81 & 20 & Moderate & 10 & $7-15$ & $7-8$ & $11-15$ \\
\hline 7 & Male & 76 & 9 & Severe & 8 & $8-12$ & $8-9$ & $10-12$ \\
\hline 9 & Female & 85 & 16 & Severe & 6 & $6-11$ & $6-8$ & $6-11$ \\
\hline 10 & Female & 80 & 20 & Mild & 7 & $7-16$ & $8-9$ & $10-16$ \\
\hline 12 & Male & 85 & 12 & Severe & 5 & $5-6$ & $5-6$ & $5-6$ \\
\hline 13 & Male & 86 & 12 & Severe & 2 & $2-5$ & $2-4$ & $2-5$ \\
\hline 14 & Male & 78 & 13 & Moderate & 13 & $8-19$ & $8-13$ & $12-19$ \\
\hline 15 & Female & 88 & 10 & Severe & 4 & $3-4$ & $3-4$ & $3-4$ \\
\hline 16 & Male & 82 & N/A & Moderate & 6 & $7-11$ & $7-8$ & $8-11$ \\
\hline 17 & Female & 93 & 23 & Mild & 12 & $11-15$ & $11-15$ & $12-15$ \\
\hline 18 & Male & 59 & 21 & Mild & 5 & $5-9$ & $5-7$ & $7-9$ \\
\hline 19 & Female & 89 & 11 & Severe & 3 & $3-4$ & $3-4$ & 4 \\
\hline 20 & Female & 86 & N/A & Moderate & 6 & 6-13 & $7-8$ & $8-13$ \\
\hline
\end{tabular}

* Some MMSE scores were older (6+ months) and did not necessarily reflect the current level of cognitive impairment. Additional notes in the client chart were used to classify participants as having mild, moderate or severe AD. N.B. Participants $8 \& 11$ were the two who withdrew.

Table 3

Regression analysis including time variable

\begin{tabular}{lccccc}
\hline Group, Treatment & \multicolumn{2}{c}{ 40 Hz RSS } & & \multicolumn{2}{c}{ Video - DVD } \\
\cline { 2 - 3 } \cline { 5 - 6 } & Intercept (standard error) & Slope (standard error) & & Intercept (standard error) & Slope (standard error) \\
\hline Mild AD, $40 \mathrm{~Hz}$ & $0.867(0.658)$ & $0.729(0.169)$ & & $1.356(0.658)$ & $-0.157(0.169)$ \\
Moderate AD, $40 \mathrm{~Hz}$ & $0.156(0.658)$ & $0.662(0.169)$ & & $-0.444(0.658)$ & $-0.138(0.169)$ \\
Severe AD, $40 \mathrm{~Hz}$ & $0.211(0.658)$ & $0.353(0.169)$ & & $0.322(0.658)$ & $0.019(0.169)$ \\
\hline
\end{tabular}

found to be $55 \%$ for the model including group, treatment, and time, meaning that $55 \%$ of the observed variation in the response is explained by these variables (see Table 3 for the Regression Analysis). Qualitatively, the slopes are positive for $40 \mathrm{~Hz}$ treatment showing an increasing SLUMS score over time (slope estimated at 0.581 which means an increase of about 0.5 for each treatment), and close to 0 or negative with DVD treatment (no change with each treatment). From Table 3, it is seen that the slopes for the three $\mathrm{AD}$ groups for $40 \mathrm{~Hz}$ are all positive and the two-sided test of the null hypothesis of a zero slope is statistically significant at the $5 \%$ level. By con- trast, the tests of the null hypothesis of zero slopes for DVD are not significant at the 5\% level. There is an indication that the increase in SLUMS scores for $40 \mathrm{~Hz}$ diminishes with the severity of $\mathrm{AD}$, but with this data the decrease was not found to be statistically significant.

The initial ANOVA (see Table 4) from the regression shows the F statistic obtained for the test of the null hypothesis that none of the predictors (group, treatment, time) has an effect. The associated $p$ value is effectively 0 . This is a good indicator that there is an effect taking place at least for some of the predictors. 


\begin{tabular}{lccc} 
& \multicolumn{2}{c}{ Table 4 } \\
ANOVA & \\
\hline Effect & df & SS & F \\
\hline Constant & 1 & 384 & \\
Predictors & 11 & 489.632 & $14.828^{*}$ \\
Error & 204 & 612.368 & \\
Total & 216 & 1486.000 & \\
${ }^{*} p<0.000001$. & & & \\
\end{tabular}

Additional tests were then undertaken to determine more precisely what effects exist. First the possibility of any interactions between group and treatment were considered. For this we compared the difference in slopes for the two treatments between mild AD and moderate $\mathrm{AD}$ and this difference was not significant at the 5\% level. Also, a comparison of the difference in the intercepts between mild $\mathrm{AD}$ and moderate $\mathrm{AD}$ was not found to be significant. Similarly there was no interaction when the severe $\mathrm{AD}$ group was taken into account. Given that no interactions were found, we next considered effects for group and for treatment. There were no effects found for group but there is a clear difference in the slope for treatment. The $t-$ statistic for comparing the slopes for $40 \mathrm{~Hz}$ and DVD equals 4.88 , which gives a $p$-value of approximately 0.000001 (see Table 5).

Based on this analysis, we can refit the model ignoring group. The relationship for $40 \mathrm{~Hz}$ is estimated to be $0.411+0.581$ (time), while for DVD it is estimated to be $0.544-0.092$ (time). These lines are plotted in Fig. 1 which shows the change in SLUMS scores for all participants and the linear trend lines for $40 \mathrm{~Hz}$ versus DVD treatments. Figure 2 shows the change in SLUMS scores regression lines for all participants.

In summary, the difference between the slopes of the lines for the two treatments is statistically significant with $p$-value approximately equal to 0.000001 . This difference in slopes implies that the treatments are different. The slope for $40 \mathrm{HZ}$ is estimated as
0.581 and this implies an improvement in SLUMS score of about a half a unit with each application of the treatment. By contrast the slope for DVD is estimated as -0.092 and this implies that there is really no improvement in SLUMS score with repeated application for this group.

\section{Qualitative results}

Researcher observation: The four predominant themes that characterize the researcher's observations for $40 \mathrm{~Hz}$ were: increased awareness of surroundings (13 participants); increased interaction (13 participants); stimulation of discussion/storytelling (13 participants); and increased alertness (11 participants). For DVD, the four predominant themes characterizing the researcher's observations were: boredom (15 participants); increased agitation/anxiety (7 participants), quiet (7 participants), and sleep (7 participants). Table 6 provides a summary of the qualitative themes that emerged in the study.

Observed emotion rating scale: The observed emotion rating form did not appear to produce any significant contribution to the data collected. There were relatively few changes in person's affect from pre to post sessions and therefore statistical analysis was not performed on this test. It appears this test was able to verify that participants maintained a similar mood from pre to post sessions.

\section{DISCUSSION}

The quantitative results of the study are encouraging and suggest that $40 \mathrm{~Hz}$ stimulation over time can lead to increased cognition. Further studies are needed to confirm this and to assess which if any of the groups (mild, moderate, severe) benefit the most from this treatment. Participants were more confused in the DVD sessions as to why they were there and this could have added to their levels of anxiety/agitation.

Table 5

Considering the regression coefficients

\begin{tabular}{lc}
\hline Contrast & Contrast (Standard Error) \\
\hline Interaction on Slope Moderate versus Mild & $0.043(0.169)$ \\
Interaction on Intercept Moderate versus Mild & $-0.344(0.658)$ \\
Interaction Severe versus Common Moderate- Mild on Slope & $0.294(0.169)$ \\
Interaction Severe versus Common Moderate-Mild on Intercept & $-0.019(0.658)$ \\
Slope DVD versus 40 Hz & $-0.824(0.169)^{*}$ \\
Moderate versus Mild on Slope & $-0.024(0.169)$ \\
Moderate versus Mild on Intercept & $-1.056(0.658)$ \\
Severe versus Common Moderate-Mild Difference on Slope & $-0.102(0.169)$ \\
Severe versus Common Moderate-Mild Difference on Intercept & $-0.366(0.658)$ \\
*0.824/0.169=4.88, $p<0.000001$. &
\end{tabular}




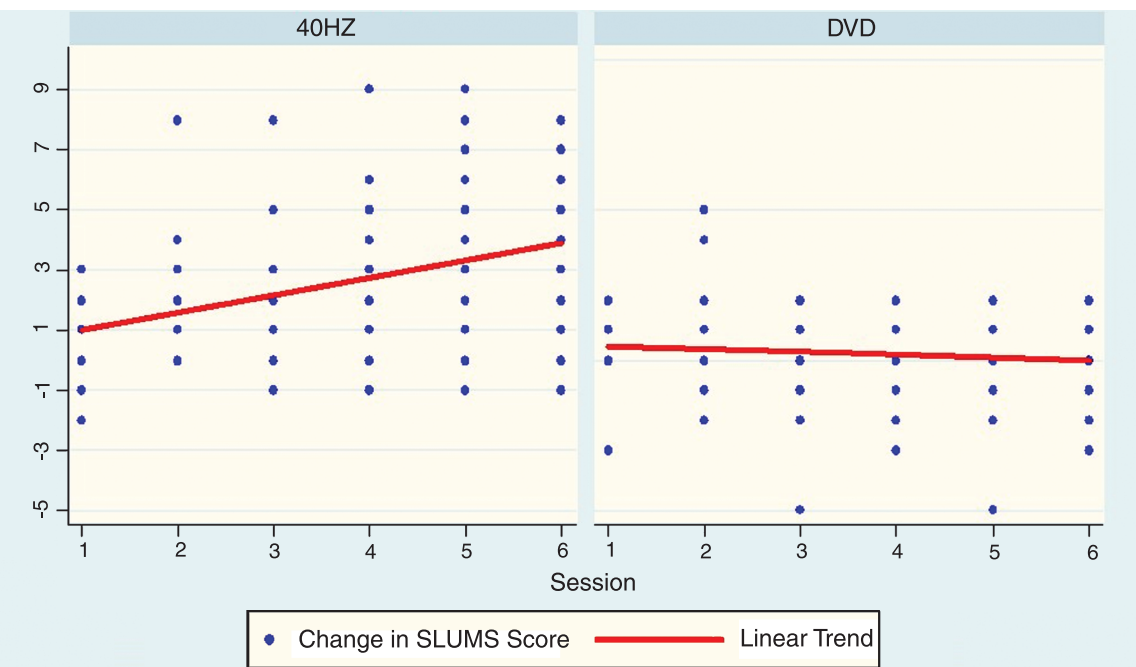

Fig. 1. All participants: Change in SLUMS score.

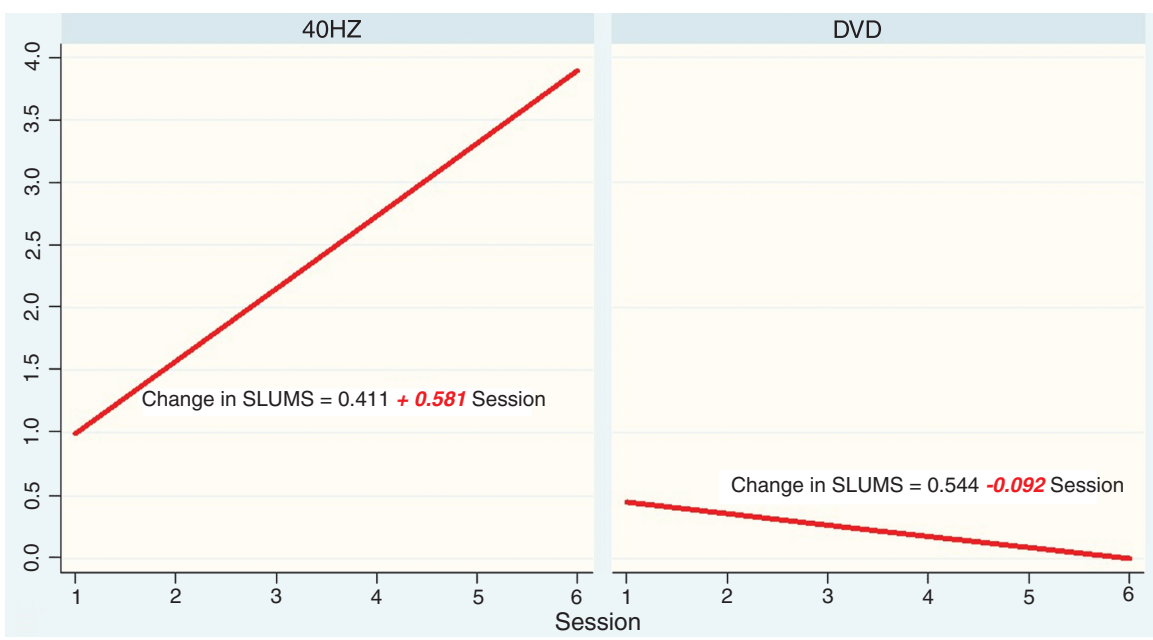

Fig. 2. All participants: Change in SLUMS score regression line.

Table 6

Qualitative themes

\begin{tabular}{lclc}
\hline DVD THEMES & $\begin{array}{c}\text { Total \& (List of Participants } \\
\text { Who Shared This Theme) }\end{array}$ & 40 HZ Themes & $\begin{array}{c}\text { Total \& (List of Participants } \\
\text { Who Shared This Theme) }\end{array}$ \\
\hline Boredom & 15 & Increased alertness & 11 \\
Increased agitation/anxiety & 7 & Increased awareness of surroundings & 13 \\
Increased suspicion/confusion & 3 & Increased clarity & 4 \\
Quiet & 7 & Increased interaction & 13 \\
Restlessness & 3 & Reminiscence & 6 \\
Sleep & 7 & Stimulation of discussion/storytelling & 13 \\
\hline
\end{tabular}

The DVD did not prove to be stimulating, but rather induced a more quiet and sleepy mood. Interestingly, the DVDs are designed to calm a person with AD, and while they did facilitate sleep and quieter states of being, they did not have an effect on reducing anx- iety/agitation. $40 \mathrm{~Hz}$ treatment appeared to have the largest impact on persons having mild to moderate AD.

The premise of this study and the possible explanation for the findings are the effect of RSS on the power 
of the oscillatory coherence in gamma at $40 \mathrm{~Hz}$. The scientific foundation for an oscillatory theory of $\mathrm{AD}$ is not well developed but the most applicable theory, thalamocortical dysrhythmia, suggests that AD is characterized by an increase in power in lower delta and theta frequencies [24] and a decrease in power in the alpha, beta, and gamma frequencies [23, 25-27]. Research points to a relationship between coherent oscillation activity in the gamma band and cognitive functions that is organized by the thalamo-corticothalamic system [28]. Specifically, research shows that with $\mathrm{AD}$ there is a decrease in the power levels around $40 \mathrm{~Hz}[8,29]$, although there also seems to be a general decrease in this level with cognitive decline and aging [30, 31]. Some research argues that there is an increase in gamma band power with $\mathrm{AD}[24,32]$; however, this research did not filter $40 \mathrm{~Hz}$ but looked at the full $30-100 \mathrm{~Hz}$ band. Also, it looked primarily at evoked response levels rather than at spontaneous activity. In general there is support for the potential that altered theta and gamma rhythms may be a functional early biomarker for $\mathrm{AD}$ [33].

Brain stimulation for $\mathrm{AD}$ is at the beginning exploratory stage. Deep brain stimulation is being used with the basic high frequency $130 \mathrm{~Hz}$ [34]. Studies in repetitive transcranial magnetic stimulation are using $20 \mathrm{~Hz}$ [35]. In terms of low frequency sound and vibrotactile stimulation, there is evidence that gamma-band oscillation can be modulated with sensory stimulation [27]. It has also been shown that stimulating a particular frequency results in multiples and partials of that frequency also being stimulated [36]. Stimulation of $40 \mathrm{~Hz}$ can be expected to produce a response at $80 \mathrm{~Hz}$ and $120 \mathrm{~Hz}$ as well as at $20 \mathrm{~Hz}$. Since $40 \mathrm{~Hz}$ seems generally implicated in intra-brain communication [37, 38], may stimulate neural outgrowth [39], shows a decrease with the onset of $\mathrm{AD}$, and has the potential to drive gamma response with auditory or somatosensory stimulation [11, 35, 40], $40 \mathrm{~Hz}$ appears to be a logical frequency for brain stimulation in $\mathrm{AD}$ patients and this study provides some evidence of its effect.

\section{Limitations}

Finding a tool to accurately measure small changes in cognition is challenging. While the SLUMS test worked well overall in this study, it would be helpful to include neuroimaging to detect changes that may be occurring pre to post session as well as over the entire treatment period. A limitation of this study was also the frequency of sessions provided. Ideally sessions would be offered three times per week or even more often. This, however, was not possible as the participants often found it challenging enough to arrange their schedules to attend the sessions two times per week. Future research is needed to address the potential mechanism involved by use of EEG or MEG. As well, research is needed to understand the extent of the cognitive effect before change plateaus as well as the duration of the effect.

\section{Conclusion}

This cross-over pilot study sought to evaluate the effects of RSS at $40 \mathrm{~Hz}$ in $18 \mathrm{AD}$ patients at three stages of the disease. Outcome measures included the SLUMS, the Observed Emotion Rating Scale, and behavioral observation by the researcher. Results indicated that the $40 \mathrm{~Hz}$ treatments were effective at increasing the slopes for the full sample and subgroups all significant beyond alpha $=0.05$, while those for the DVD were not. The thematic analysis of qualitative observations also supported the statistical findings and a number of themes arose including increased awareness of surroundings for post $40 \mathrm{~Hz}$ treatment and boredom for the post DVD treatment. Results are promising for the potential $40 \mathrm{~Hz}$ treatment may have on improving mental function as measured by SLUMS in persons with AD, however further research is needed.

\section{ACKNOWLEDGMENTS}

The following persons were members of the collaborative research team: Dr. Malcolm Binns, $\mathrm{PhD}$, Baycrest Centre; Dr. Bernard Ross, PhD, Baycrest Centre; Dr. Rebecca Renwick, University of Toronto; Dr. Sharon Cohen, University of Toronto; Dr. Angela Colantonio, University of Toronto. This project was funded with a gift to the Music and Health Research Collaboratory, University of Toronto MaHRC by Mr. Jerry Heffernan.

Authors' disclosures available online (http:// j-alz.com/manuscript-disclosures/16-0081r1).

\section{SUPPLEMENTARY MATERIAL}

The supplementary material is available in the electronic version of this article: http://dx.doi.org/ 10.3233/JAD-160081. 


\section{REFERENCES}

[1] Government of Canada, National Dementia Research and Prevention Plan. http://healthycanadians.gc.ca/diseasesconditions-maladies-affections/disease-maladie/dementiademence/plan-eng.php, Last updated September 2, 2014, Accessed on May 22, 2015.

[2] Braak H, Del Tredici K (2012) Where, when, and in what form does sporadic Alzheimer disease begin? Curr Opin Neurol 6, 708-714.

[3] Ballard C, Khan Z, Clack H, Corbett A (2011) Nonpharmacological treatment of Alzheimer Disease. Can J Psychiatry 56, 589-595.

[4] Alzheimer's Society of Canada (2005) Non-pharmacological therapies for the treatment of behavioural symptoms in people with dementia, http://www.alzheimers.org.uk/ site/scripts/download_info.php?fileID=271, Accessed May 22, 2015.

[5] Alzheimer Society of Canada, Complementary and Alternative Health Care, http://www.alzheimer.ca/en/About-demen tia/Treatment-options/Complementary-and-alternativehealth-care. Last updated October 28, 2015, Accessed on May 22, 2015.

[6] Olazaran J, Reisberg B, Clare L, Cruz I, Peña-Casanova J, Del Ser T, Woods B, Beck C, Auer S, Lai C, Spector A, Fazio S, Bond J, Kivipelto M, Brodaty H, Rojo JM, Collins H, Teri L, Mittelman M, Orrell M, Feldman, HH, Muñiz R (2010) Nonpharmacological therapies in Alzheimer's disease: A review of efficacy. Dement Geriatr Cogn Disord 30, 161178.

[7] Turpie I (2014) Global aging: Challenges and opportunities from a health care perspective. Presented at: Landscapes of Aging CAG conference, October 2014, Niagara Falls, ON.

[8] Ribary U, Ioannidest AA, Singht KD, Hassont R, Boltont JPR, Lado F, Mogilner A, Llinas R (1991) Magnetic field tomography of coherent thalamocortical $40-\mathrm{Hz}$ oscillations in humans. Proc Natl Acad Sci U S A 88, 11037-11041.

[9] Llinas R, Ribary U (1993) Coherent 40-HZ oscillation characterizes dream state in humans. Proc Natl Acad Sci U S A 90, 2078-2081.

[10] Jefferys JGR, Traub RD, Whittington MA (1996) Neuronal networks for induced ' $40 \mathrm{~Hz}$ ' Rhythms. Trends Neurosci 19, 202-208

[11] Ross B, Jamali S, Miyazaki T, Fujioka T (2013) Synchronization of beta and gamma oscillations in the somatosensory evoked neuromagnetic steady-state response. Exp Neurol 245, 40-51.

[12] Bartel L (2013) Vibroacoustic therapy. In International Dictionary of Music Therapy, Kirkland, K, ed. Routledge, New York, pp. 138.

[13] Bartel L (2013) Physioacoustic method. In International Dictionary of Music Therapy, Kirkland, K, ed. Routledge, New York, pp. 99.

[14] Bartel L (2013) Low frequency sound therapy. In International Dictionary of Music Therapy, Kirkland, K, ed. Routledge, New York, pp. 70-71.

[15] Wigram T (1997) The effect of vibroacoustic therapy compared with music and movement based physiotherapy on multiply handicapped patients with high muscle tone and spasticity. In Music Vibration and Health, Wigram T, Dileo C, eds. Jeffery Books, Cherry Hill, NJ, pp. 69-85.

[16] Karkkainen M, Mitsui J (2006) The effects of sound based vibration treatment on the human mind and body: The physioacoustic method. J Int Soc Life Inform Sci 24, 155-159.
[17] Zheng A, Sakari R, Cheng SM, Hietikko A, Moilanen P, Timonen J, Fagerlund KM, Kärkkäinen M, Alèn M, Cheng S (2009) Effects of a low-frequency sound wave therapy programme on functional capacity, blood circulation and bone metabolism in frail old men and women. Clin Rehabil 23, 897-908.

[18] McKhann GM, Knopman DS, Chertkow H, Hyman BT, Jack CR Jr, Kawas CH, Klunk WE, Koroshetz WJ, Manly JJ, Mayeux R, Mohs RC, Morris JC, Rossor MN, Scheltens P, Carrillo MC, Thies B, Weintraub S, Phelps CH (2011) The diagnosis of dementia due to Alzheimer's disease: Recommendations from the National Institute on Aging and the Alzheimer's Association workgroup. Alzheimers Dement 7, 263-269.

[19] American Psychiatric Association (2000) Diagnostic and statistical manual of mental disorders: DSM-IV-TR. Washington, DC.

[20] Next Wave Headquarters, Next Wave Physioacoustic MX therapy chair, http://www.nextwaveworldwide.com/ products/physioacoustic-mx-therapy-chair/, Accessed on May 22, 2015.

[21] The Best Caribbean Beaches. Dir. Greg Voevodsky. Powerfloe Network. 2003, DVD.

[22] Tariq SH, Tumosa N, Chibnall JT, Perry III HM, Morley JE (2006) The Saint Louis University Mental Status (SLUMS) Examination for detecting mild cognitive impairment and dementia is more sensitive than the Mini-Mental Status Examination (MMSE) - A pilot study. Am J Geriatr Psychiatry 14, 900-910.

[23] Lawton MP, Van Haitsma K, Klapper JA (1999) Observed Emotion Rating Scale, Madlyn and Leonard Abramson Centre for Jewish Life, http://www.abramsoncenter.org/PRI, Accessed May 22, 2015.

[24] Huang C, Wahlund LO, Dierks T, Julin P, Winblad B, Jelic B (2000) Discrimination of Alzheimer's disease and mild cognitive impairment by equivalent EEG sources: A crosssectional and longitudinal study. Clin Neurophysiol 111, 161-167.

[25] Van Deursen J (2009) Functional and structural brain markers of Alzheimer's disease: Clinical studies using EEG and VBM. NeuroPsych Publishers, Maastricht, The Netherlands.

[26] Jeong J (2004) EEG dynamics in patients with Alzheimer's disease. Clin Neurophysiol 115, 1490-1505.

[27] van Deursen JA, Vuurman EFPM, Verhey FRJ, van KranenMastenbroek VHJM, Riedel WJ (2008) Increased EEG gamma band activity in Alzheimer's disease and mild cognitive impairment. J Neural Transm 115, 1301-1311.

[28] Ribary U (2005) Dynamics of thalamo-cortical network oscillations and human perception. In Progress in Brain Research, Laureys S, ed. 150, 127-142.

[29] Ribary U, Llinas R, Kluger A, Cappell J, Suk J, Ferris SH (1990) Dynamics of magnetic auditory evoked steady-state responses in Alzheimer patients. Electroencephalogr Clin Neurophysiol Suppl 75, S126.

[30] Paul RH, Clark RC, Lawrence J, Goldberg E, Williams LM, Cooper N, Cohen RA, Brickman AM, Gordon E (2005) Age-dependent change in executive function and gamma $40 \mathrm{~Hz}$ phase synchrony. J Integr Neurosci 4, 63-76.

[31] Griskova-Bulanova I, Dapsys K, Maciulis V (2013) Does brain ability to synchronize with $40 \mathrm{~Hz}$ auditory stimulation change with age? Acta Neurobiol Exp 73, 564-570.

[32] Osipova D, Pekkonen E, Ahveninen J (2006) Enhanced magnetic auditory steady-state response in early Alzheimer's disease. Clin Neurophysiol 117, 1990-1995. 
[33] Goutagny R, Krantic S (2013) Hippocampal oscillatory activity in Alzheimer's disease: Toward the identification of early biomarkers? Aging Dis 4, 134-140.

[34] Lozano AM, Lipsman N (2013) Probing and regulating dysfunctional circuits using deep brain stimulation. Neuron 77 , 406-424.

[35] Cotelli M, Calabria M, Manenti R, Rosini S,Zanetti O, Cappa SF, Miniussi C (2011) Improved language performance in Alzheimer disease following brain stimulation. J Neurol Neurosurg Psychiatry 82, 794-797.

[36] Jamali S, Ross B (2013) Somatotopic finger mapping using MEG: Toward an optimal stimulation paradigm. Clin Neurophysiol 124, 1659.

[37] Fries P (2005) A mechanism for cognitive dynamics: Neuronal communication through neuronal coherence. Trends Cogn Sci 9, 474-480.
[38] Ward LM (2003) Synchronous neural oscillations and cognitive processes. Trends Cogn Sci 7, 553-559.

[39] Koike Y, Iwamoto S, Kimata Y, Nohno T, Hiragami F, Kawamura K, Numata K, Murai H, Okisima K, Iwata M, Kano Y (2004) Low-frequency vibratory sound induces neurite outgrowth in PC12m3 cells in which nerve growth factor-induced neurite outgrowth is impaired. Tiss Cult Res Commun 23, 81-90.

[40] Patel A (2003) A new approach to the cognitive neuroscience of melody. In The Cognitive Neuroscience of Music, Peretz I, Zatorre R eds. Oxford University Press, Oxford, pp. 325-345. 